\title{
TOUGHVISUAL:A Friendly Graphical User Interface For Building Toughreact Models Under Complex 3d Geological Environments
}

\author{
Yanlin Yang, Tianfu Xu, Fanting Bu, Hongwu Lei, Yan Shi, Guangrong Jin, Fugang Wang* \\ Key Laboratory of Groundwater Resources and Environment, Ministry of Education, Jilin University, Changchun, 130021, \\ China \\ * Tel:18650009371; Fax:+86-431-88502606; e-mail:wangfugang@jlu.edu.cn
}

\begin{abstract}
TOUGHVISUAL is a full Windows-based graphical user interface for the TOUGHREACT program. TOUGHREACT is a general multiphase multicomponent reactive transport simulator, developed by introducing geochemistry into the multiphase fluid and heat flow code TOUGH2. TOUGHREACT has been widely used internationally for $\mathrm{CO} 2$ geological sequestration, nuclear waste disposal, groundwater remediation and geothermal energy development. The complexity of the input files (such as "flow.inp", "solute.inp" and "chemical.inp") required by original TOURHREACT, makes manual construction of these input files tedious and error-prone, especially dealing with complex geological structures and irregular study region. For this reason, we attempted to develop a new user-friendly interface. Here, we present a description and application examples of the improved pre- and post-processing graphical user interface TOUGHVISUAL. This interface can interactively create geometrical models, define related properties for multiphase flow and reactive transport, run the model, and view the simulation result. The interface offers a conceptual model approach and local grid refinement. It can deal with complex geological condition and heterogeneous media, and can share file data with other software to build a field-scale model.
\end{abstract}

Keywords-Interface software; Mesh generation; Output visualization; TOUGHREACT; Numerical model.

\section{INTRODUCTION}

TOUGHREACT is a general multiphase multicomponent reactive transport simulator in porous and fractured media $[19,20,21]$. It was initially developed as a powerful research tool. However, it is certainly quite significant hurdles for new users. The input files, requiring using a text-based editor and assigning properties to grid elements, are difficult to create. It is especially inconvenient if the study area is irregular with complex geological structure or heterogeneous porous media. There are a few commercial programs, such as PetraSim, Wingridder, GeoCAD, Tougher, making graphical interfaces for TOUGH family of codes[1, 2, 14, 16, 23, 25], but they are not very flexible, convenient, and user-friendly. For example, the Tougher interface software does not create all the files to run TOUGHREACT. Considering the shortage of existing interfaces and functional requirements for new users, we attempted to develop an improved interface with better working environment for TOUGHREACT, making it more user-friendly and convenient.
The interface presented here is a fully integrated package combining TOUGHREACT with the most intuitive and powerful graphical interface available. We adopts the ideal of modularization architecture. The program can be divided into several modules, according to the function. Certainly, each module would include some sub-modules. The innovative menu structure allows you to easily dimension the model domain and conveniently assign model properties and boundary conditions, run model simulations and visualize the results with 3D iso-surfaces, color shading or animation, which can be set in an interactive fashion. The model grid, input parameters, and results can be visualized in crosssection or plan view at any time during the development of the model. With this interface, one would find that it is very easy to generate and edit a conceptual TOUGHREACT or TOUGH2 model.

In this paper, we first describe main features, design structures, and geometrical model of this interface in detail. Then, we present two application examples for how it can be used to set up a model, to run simulation and to visual simulation results.

\section{TOUGHVISUAL FEATURES}

The TOUGHVISUAL interface (Fig. 1) has been specifically designed to increase modeling productivity and decrease the complexities typically associated with building nonisothermal multiphase flow and multicomponent reactive transport models. Regarding the structure design for this graphical interface, we used the Microsoft Visual Studio 2005 as the development tool, while utilized OpenGL to render the model and visualize the result. A manageable and upgrade ideal of the modularization architecture is adopted. Its portion structure directly related to TOUGHREACT is shown in Fig. 2.

The program allows users to graphically assign, and edit all of the necessary input parameters for building a model. It allows you to generate regular or irregular geometry models, and to use data from many other geological softwares. User can select, customize, and overlay the various display options for presenting the modeling through the output menus. The interface allows you to display all of the modeling results for dynamic analysis after running the model without delay. It provides some instructions to users on how to do and what to do during modeling, so it is very flexible and friendly. 


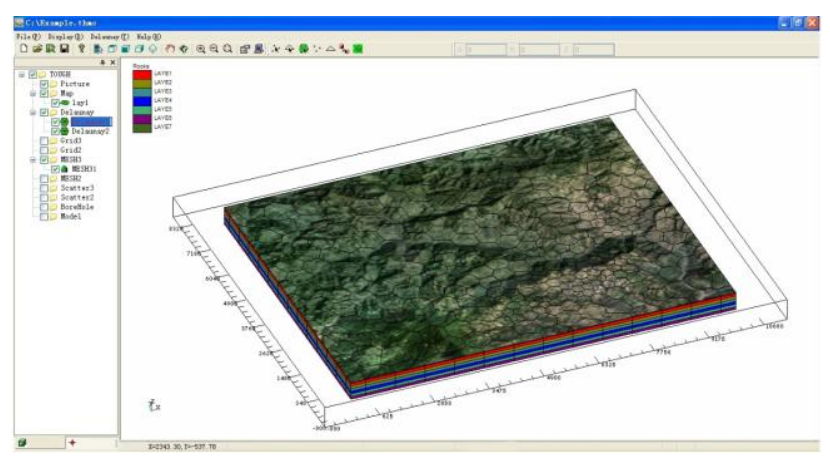

Figure 1. Main window of the TOUGHVISUAL interface software.

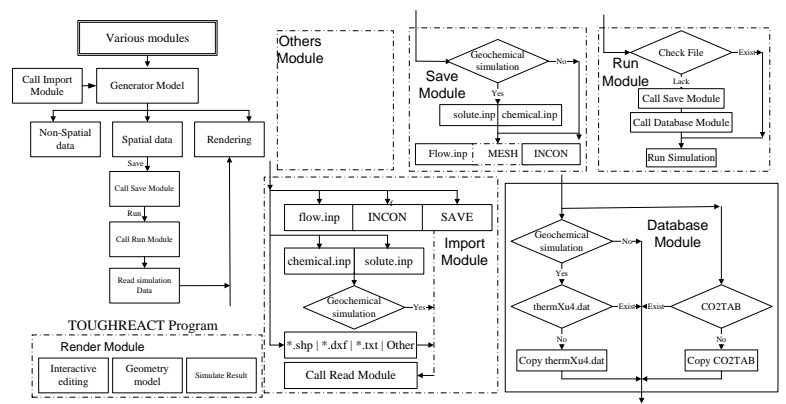

Figure 2. Portion structure chart showing how TOUGHVISUAL is related to TOUGHREACT

As can be shown in Fig. 1, the left data tree allows the user directly access to control the model, turning display on or off, converting data to other modules, and activating the module for editing. One will find that this data management mode is much convenient in this specialized system. A manageable and upgrade ideal of the modularization architecture is adopted. Its portion structure, directly related to TOUGHREACT, is shown in Fig. 2. In the following Sections, Geometrical Model, Model Properties, Interaction With Other Modules, Model Generation and Visualization will be discussed in great detail.

\section{GEOMETRICAL MODEL}

The geometrical model generator is one of the most important and critical part of a interface software. This is because the numerical scheme, used in TOUGHREACT code, is based on the Integral Finite Difference (IFD) method [12], and the shape of discretization grid can be regular or irregular in three dimensions.

Using this interface, one can use the mouse to draw the simulation domain boundary, and also one can specify the boundary through study area coordinates. Then, the computing grids are automatically generated by clicking the related menu. The number of geological layers is unrestricted. Although the mesh maker ("MESHMAKER") embedded in the original TOUGH codes has a capability in handing the wide variety of grid information required to describe complex objects, designing and generating a suitable irregular grid can be tedious and error-prone, and the maximum number of grid blocks must be less than 1 million in mesh maker. With a new block's naming method in the current interface, the maximum blocks number can reach as many as 23 million $(62 * 62 * 62 * 10 * 10)$ for a high resolution model. The interface can also generate input file for TOUGH-MP [25], a parallel version of the TOUGH code.

This interface has offered three frequently-used methods to generate a geometrical model. First, one can generate a 3D geometrical model directly, like regular grid model which needs to specify the number of cells in $\mathrm{x}, \mathrm{y}$ and $\mathrm{z}$ direction and sizes of each cell. Second, one can initially create an unstructured mesh in 2D, like Voronoi using the Delaunay [5, $7,13,17]$ triangulation to create, and then one introduces topological structure to a 3D mesh generation, during which one needs to assign the number of geological layers and the elevation of each layer. The last method to generate a geometrical model is from other package's transformation, such as geologic model. The former two approaches are displayed in Fig. 3 and 4.

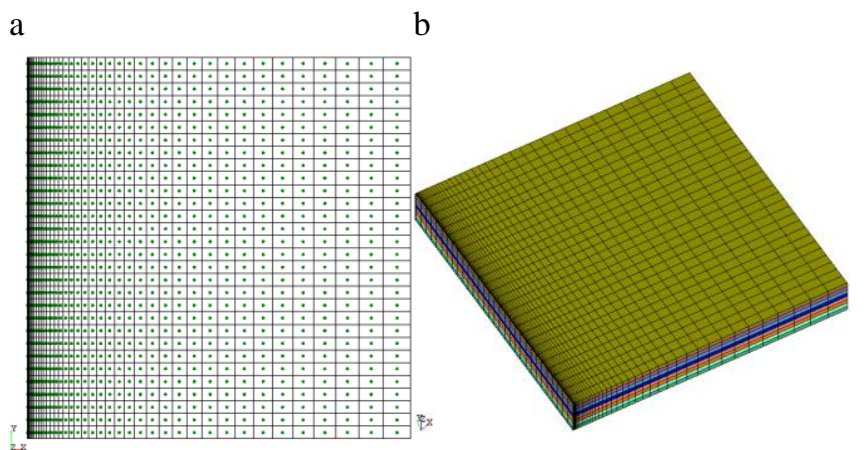

Figure 3. Typical regular grid model: (a) Layout of one layer, (b) 3D model after editing.

a

b

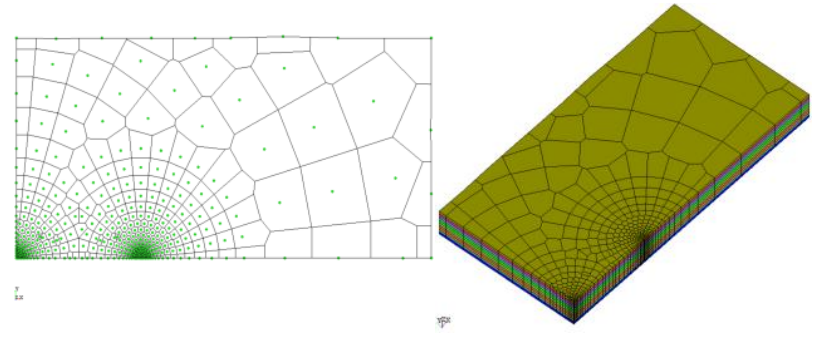

Figure 4. Typical irregular grid model: (a) Layout of one layer, (b) Displaying in 3D.

Fig. 3 shows a regular geometrical model. Note that the element size can be edited interactively in order to meet the user's needs. The rectangular grid has many merits, at first the data structure is very simple, it needs to just record the three direction coordinates, no need to record the topological data, and the maximum connection number for each block is only six. Therefore, this rectangular grid can greatly reduce computation time and storage space. Fig. 4a displays an irregular geometrical model in 2D. The green points are the center of elements. The element (or cell) size is smaller near the injection/production point at the bottom left. It is easy to produce high resolution cells to improve the model calculation accuracy in the fault or key study area. Fig. 4b is 
the corresponding 3D model. The user can also certainly change the elevation within 3D models.

The entire geometric information of the space discretization, generated in the above processes, is provided in the "MESH" file. The "MESH" gives a list of grid block volumes $V_{n}$, interface areas $A_{n m}$ between two adjacent grid blocks, nodal distances $D_{n m}$, and component $g_{n m}$ of gravitational acceleration along nodal lines. Calculation of these parameters is the most important. This interface program adopts the following methods to achieve it.

The distance calculation mainly refers to the point-plane distance in the "MESH" file. Generally, it is very easy to calculate for the regular grid $\left(d_{1}=\left(x_{i}-x_{i-1}\right) / 2\right.$, $d_{2}=\left(x_{i+1}-x_{i}\right) / 2$, see Fig. 5a). While the normally nodal distance calculation $\left(D_{n}, D_{m}\right.$ in Fig. $5 \mathrm{~b}, \mathrm{c}$ ) can use Equation 1 , which will consume much more computer time than prior.

a
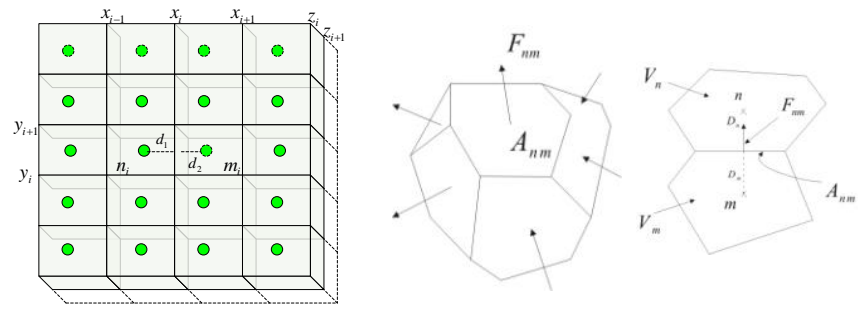

Figure 5. Schemetic representation of nodal distance, interface area, and element volume: (a) regular grid, and $(b, c)$ irregular grid

Let's take on not coplanar three points in an arbitrary cross section, $\left(x_{1}, y_{1}, z_{1}\right),\left(x_{2}, y_{2}, z_{2}\right),\left(x_{3}, y_{3}, z_{3}\right)$, then the corresponding plane equation is $\pi: A x+B y+C z+D=0$, with $A=\left(y_{2}-y_{1}\right) \times\left(z_{3}-z_{1}\right)-\left(y_{3}-y_{1}\right) \times\left(z_{2}-z_{1}\right)$, $B=\left(x_{3}-x_{1}\right) \times\left(z_{2}-z_{1}\right)-\left(x_{2}-x_{1}\right) \times\left(z_{3}-z_{1}\right), C=\left(x_{2}-x_{1}\right) \times\left(y_{3}-y_{1}\right)-\left(x_{3}-x_{1}\right) \times\left(y_{2}-y_{1}\right)$, $D=-(A \times x 1+B \times y 1+C \times z 1)$, respectively. The centre point of one block is $\left(x_{0}, y_{0}, z_{0}\right)$, then, the point-plan distance is given by [9]

$$
D=\left|A x_{0}+B y_{0}+C z_{0}+D\right| / \sqrt{A^{2}+B^{2}+C^{2}}
$$

Grid block's surface area or sectional area can be solved with the formula of simple polygon area. However, for irregular grid, we must use (2) [8] to compute the area of an interface of any polygon with $N$ vertices $P_{i}(i=1 \cdots N)$. This formula for computing interface area is very effective for any polygon in $2 \mathrm{D}$ or $3 \mathrm{D}$.

$$
S=\frac{1}{2} \sum_{i=1}^{N} P_{i} \times P_{i+1}
$$

For 2D, where $P_{i}=\left(x_{i}, y_{i}\right)$, then the formula can be given by $S=\frac{1}{2} \sum_{i=1}^{n}\left(x_{i} y_{i+1}-x_{i+1} y_{i}\right)$. For $3 \mathrm{D}$, where $P_{i}=\left(x_{i}, y_{, i}, z_{i}\right)$, area formula can be written as $S=1 / 2\left[\cos (n, z) \sum_{i=1}^{n}\left(x_{i} y_{i+1}-x_{i+1} y_{i}\right)+\cos (n, x) \sum_{i=1}^{n}\left(y_{i} z_{i+1}-y_{i+1} z_{i}\right)+\cos (n, y) \sum_{i=1}^{n}\left(z_{i} x_{i+1}-z_{i+1} x_{i}\right)\right.$ , with $\cos (n, x), \cos (n, y), \cos (n, z)$, are the cosine of angle between plane vector with coordinate axis respectively.

Yet, the volume of a polyhedron $\mathrm{R}[6,8]$, with $N$ vertices and $m$ faces $\left(F_{1}, F_{2}, \cdots, F_{m}\right)$, is given in (3). Calculation of these parameters needs first to transform complex polyhedron into a simple polyhedron, then computes its volume.

$$
V=\frac{1}{3} \sum_{j=1}^{m} F_{j} \bullet A_{j}
$$

where, $F_{j}$ is the average value of the inward normal component of $F ; A_{j}$ is the vector area of $F_{j}, V$ is the element volume.

The cosine of the angle between the gravitational acceleration vector and the line between the two elements for the "CONNE" data in the "MESH" file is required to calculate. One first set the direction of gravitational acceleration in the model, then this visual software will automatically compute the cosine value. Assuming the gravitational direction is $g_{n m}=\left(x_{g}, y_{g}, z_{g}\right)$ (Fig. 6), so the connected element $(m, n)$ vector is $L_{n m}=\left(x_{m}-x_{n}, y_{m}-y_{n}, z_{m}-z_{n}\right)$. The Calculation formula can be expressed as (4).

$\cos (\theta)=g_{n m} \cdot\left\llcorner_{n m}^{\prime}=\frac{x_{g} \times\left(x_{m}-x_{n}\right)+y_{g} \times\left(y_{m}-y_{n}\right)+z_{g} \times\left(z_{m}-z_{n}\right)}{\sqrt{\left(x_{g}{ }^{2}+y_{g}{ }^{2}+z_{g}{ }^{2}\right) \times\left[\left(x_{m}-x_{n}\right)^{2}+\left(y_{m}-y_{n}\right)^{2}+\left(z_{m}-z_{n}\right)^{2}\right]}}\right.$

where

$$
\begin{aligned}
& L_{n m}^{\prime}=\frac{1}{\sqrt{\left(x_{m}-x_{n}\right)^{2}+\left(y_{m}-y_{n}\right)^{2}+\left(z_{m}-z_{n}\right)^{2}}}\left(x_{m}-x_{n}, y_{m}-y_{n}, z_{m}-z_{n}\right) \\
& g_{n m}{ }^{\prime}=\frac{1}{\sqrt{x_{g}{ }^{2}+y_{g}{ }^{2}+z_{g}{ }^{2}}}\left(x_{g}, y_{b}, z_{g}\right)
\end{aligned}
$$

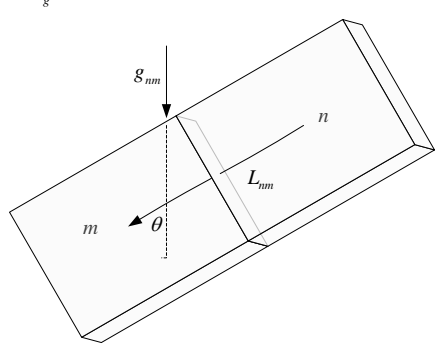

Figure 6. Cosine of the angle between the gravitational acceleration and the line between the two adjacent elements.

Now, geometric properties (element volume, interface area, nodal distance between two connected grid blocks, and 
cosine value) for all grid blocks have be specified, so the "MESH" file can now be generated.

\section{MODEL PROPERTIES}

TOUGH simulator's input files data are divided into many individual keyword data blocks. Different Keyword data blocks provide different information, such as "ROCKS", "GENER", "INCON", "PARAM", "TIMES". A suitable user interface can guide the user in the model definition process, and it can ease learning for a beginner user. For a new model, many element's properties can inherit the default value, if needed one can change it later.

\section{A. Initial Input of Model Properties}

\section{1) Material Properties}

It mainly introduces ROCK's properties, which could be set by the material tab (Fig. 7). In default, all grid blocks are assigned the first material. The interface allows user to edit a selected material and to change block's material according to the study area's geological conditions [21]. When the user saves the model, these values will be written into the "flow.inp" file, according to the original TOUGH2 fixed format.

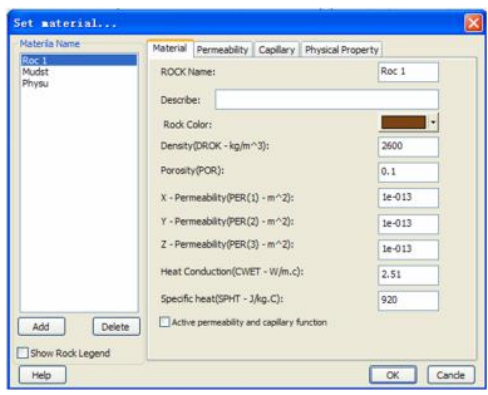

Figure 7. Dialog box setting for rock material zone parameters.

\section{2) Geochemical System Parameters}

In additional to the system of multiphase fluid and heat flow as the capability of TOUGH2, geochemical system can be defined with this interface software. Geochemical system contains aqueous species, minerals, gases, surface complexes, species with linear adsorption $\mathrm{Kd}$ and radioactive decay, and exchangeable cations, and initial chemical conditions (Xu et al., 2005). Fig. 8a and b show that the user must set aqueous species and mineral. Fig. 8c and d allows the user to select the initial composition of primary species and mineral respectively.

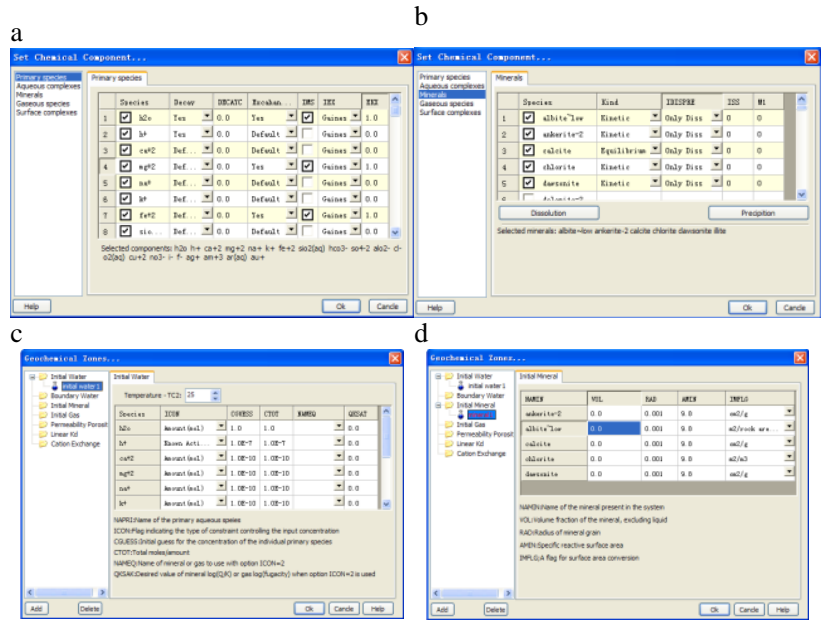

Figure 8. User interface for the "chemical.inp" file: (a) Interface for primary species, (b) Mineral phase constants, (c) Initial composition of primary species, (d) Chemical zone for mineral phases.

\section{3) Transport Parameters}

Transport parameters are included in the "solute.inp". The dialog in Fig. 9 shows how these parameters can be set. Fig. 9a lists the iteration scheme between transport and reaction, and linear solver for transport. Fig. 9b shows the options for reactive geochemical transport.
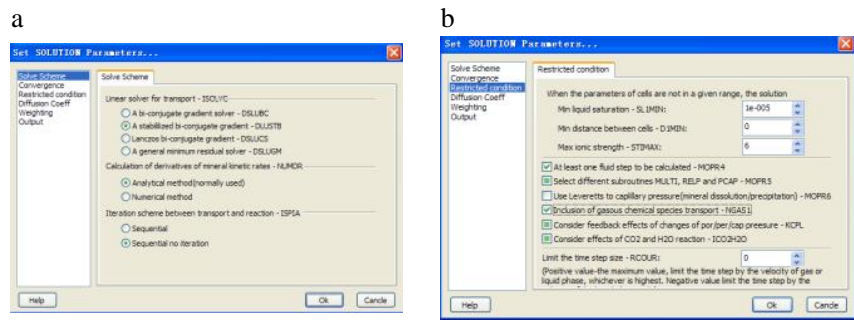

Figure 9. Data set for "Solute.inp" file: (a) User interface for iteration solution scheme, and (b) Run constraints.

\section{4) Other Properties}

Similar organization is used for some other parameters as previously mentioned. Here we only illustrate some of these parameters (output control, GENER and initial condition).

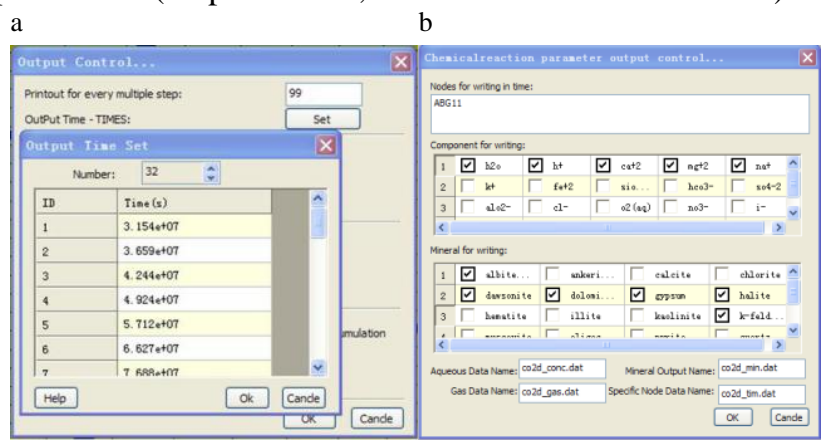

Figure 10. Dialog box for output control: (a) Output time control, (b) Grid blocks, components, minerals for printout. 
If one wants to obtain result printout at specified times, the setting method is illustrated in Fig. 10a. The total number of printout times desired have to be less than 100. Similarly, this tab (Fig. 10b) reveals the method for chemical component printout.

\begin{tabular}{|c|c|c|c|c|c|}
\hline \multicolumn{6}{|c|}{ Sink/Source data set... } \\
\hline \multicolumn{3}{|c|}{ Inject type: Injecct $\mathrm{CO} 2$} & \multicolumn{2}{|c|}{ Number Time Part: 4} & $\square$ Constant \\
\hline ID & Inject Type & Rate & Enthalpy & Time & Cell \\
\hline 1 & Inject $\mathrm{C02}$ & 8 & 0 & 0 & $\begin{array}{l}\text { 11ABA1ABBB } 11 A \\
\text { BI11ABJ11AB } 11\end{array}$ \\
\hline 2 & Inject $\mathrm{C02}$ & 4 & 0 & 3. $15 \mathrm{e}+008$ & $\begin{array}{l}\text { ABL11ABST1ABBT } \\
\text { 11ABU11ABV11A }\end{array}$ \\
\hline 3 & Inject $\mathrm{C} 02$ & 2 & 0 & 6. $31 \mathrm{e}+008$ & 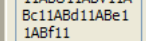 \\
\hline \multirow[t]{2}{*}{4} & Inject $\mathrm{C02}$ & 0 & 0 & 3. $15 \mathrm{e}+009$ & MOP(12) set: \\
\hline & & & & & Linear interpola $\checkmark$ \\
\hline \multicolumn{2}{|c|}{ Help } & & & & Ok Cande \\
\hline
\end{tabular}

Figure 11. User interface for flow source/sink terms (generation section).

The user can select a source or sink grid block to inject/product mass or heat. The associated parameter values to be set are shown in Fig. 11. At the same time, $\operatorname{MOP}(12)$ parameter, determining interpolation procedure for time dependent source/sink data, can be set as well.

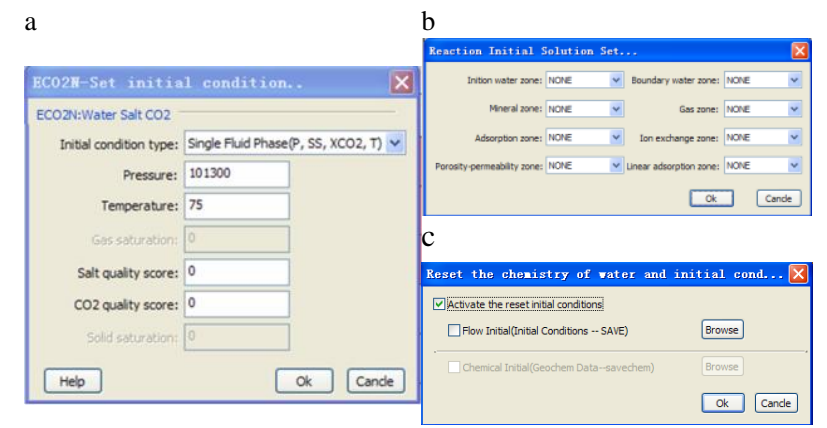

Figure 12. Definition of the initial conditions: (a) Specification of the default initial condition for the primary variables, (b) Default values for chemical property zone and (c) Connecting to existing initial condition files.

Fig. 12a introduces a set of primary variables, which are used as default initial conditions for all grid blocks that are not assigned by means of data blocks "INCON" in "flow.inp" file. Different primary variables are used for different EOS modules. When the user selects a certain EOS module, this dialog will activate the corresponding control for editing. This interface software offers to calculate initial condition for each block. The pressure will be calculated according to hydrostatic distribution. When finishing editing a block's pressure, the program will automatically check the pressure distribution, which must be less than the most upper block's pressure (and 600 bar for ECO2N, maximum pressure allowed) and more than the most lower block's pressure. The temperature is calculated according to geothermal gradient. When modifying a block's temperature, temperature can be checked as well. Similarly, temperature should be more than 12 and less than 110 degrees Celsius for ECO2N module. Fig. 12b defines the default values for chemical property zone related to grid blocks. Fig. 12c shows how a user can restart a TOUGHREACT model by renaming the $\mathrm{SAVE} / \mathrm{savechem}$ generated in a previous run, to INCON/inchem files. Then the program will take procedures for re-initialization and continue the simulation run.

\section{B. Editing Model Properties}

After geometric model generation, grid block properties may need to be edited directly for some research purposes. This can be accomplished with TOUGHVISUAL, which allows the user to select a geological layer or some grid blocks for editing, such as shown in Fig. 13a, b, and c. What's more, the user can directly see what has changed, it is very useful.

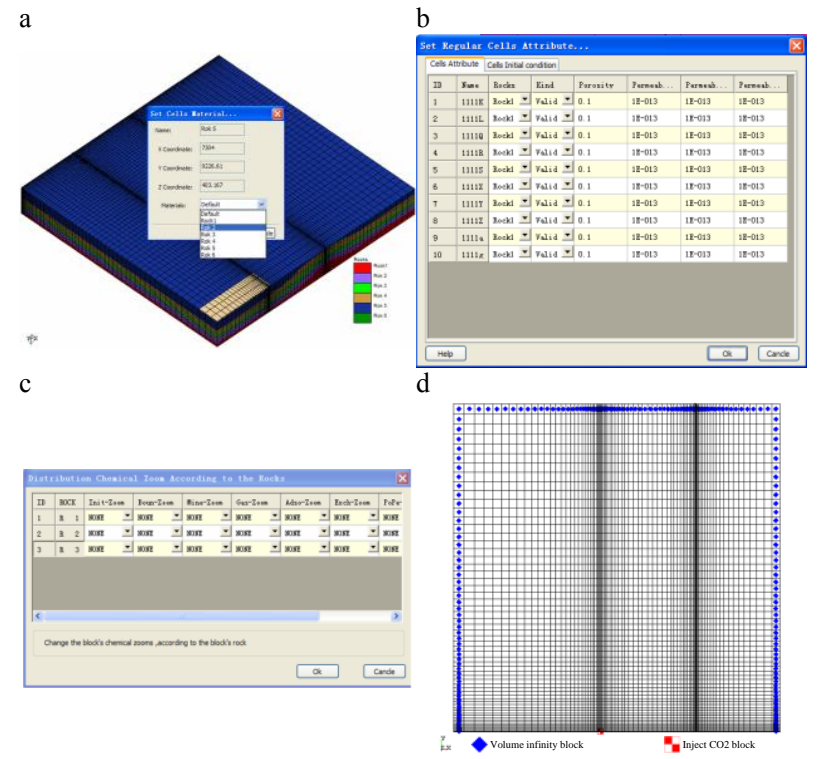

Figure 13. (a) Modification of the block's material zone number. (b) Modification of a grid block's porosity, permeability, or initial conditions. (c) Setting the chemical property zone according to block's material. (d) Grid block type identifier.

Almost all parameters can be modified through the interface. One can select some grid blocks at first, and then can overwrite it later. Fig. 13a shows that one modify block's attribute after selecting some blocks. This dialog box (Fig. 13b), including block's common attributes, could be frequently utilized. It is very simple, effective and often-used method to initial chemical zones for all blocks through the dialog in Fig. 13c. It is based on the fact that different rock materials generally have different chemical zones.

In original TOUGHREACT code, assignment of Dirchlet conditions is implemented by using very large volume grid blocks, which implicitly keeps the grid block properties (pressure, temperature and concentrations) constant during the simulation time. We kept the same approach by imposing a volume of $1.0 \mathrm{E} 30 \mathrm{~m} 3$. Fig. $13 \mathrm{~d}$ is a result diagram for the boundary conditions (use different icons for identification). 


\section{Interaction with Other Softwares}

TOUGHVISUAL can share information or data with other geological softwares. Some of typical file formats that can be read/written by this interface include, ArcGIS's Shape file, CAD's DXF files, Surfer's grd file, Petrel's inc file or regular BMP files and so on.

\section{INTERACTION WITH OTHER MODULES}

The program's modular design enables the user to select modules custom combinations, allowing the user to choose only those TOUGHREACT modeling capabilities that are required. It contains about several interdependent modules, which supply different function for each other. For example, there are many methods to modify the parameters of TOUGHREACT model, such as grid block's material property, porosity, permeability or chemical zone. Here, we just discuss how to place material zones to numerical model.

a
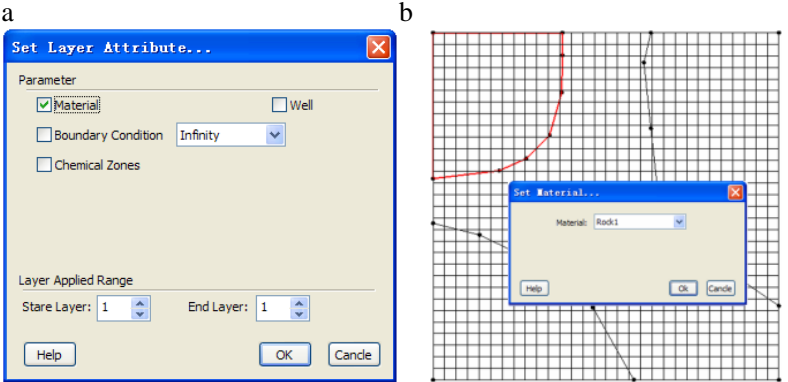

c

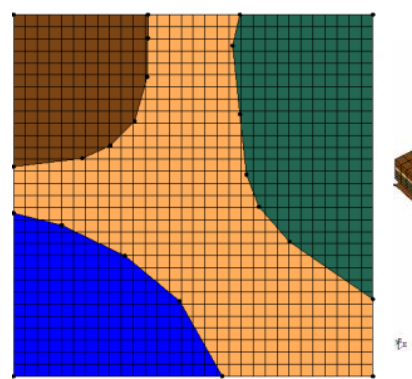

$\mathrm{d}$

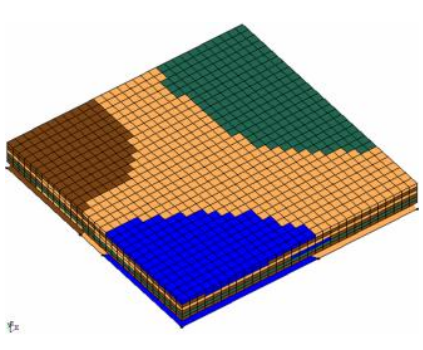

Figure 14. (a) Dialog box for assigning geological layer parameters. (b) Setting rock material zones. (c) Plotting rock material zones. (d) Place of material zones to grid blocks.

One of the most exciting strengths of this interface software is that conceptual model approach can be used. The approach presented here makes it possible to deal with large complex models in a simple and efficient manner, as shown in Fig. 14. Fig. 14a indicates which properties, including material, boundary condition or chemical zone at present, can be transformed. Fig. 14b shows assigning different rock material zones. Fig. 14c is the plot of different material zones with different colors. Carrying out the related command from the menu, the property would be automatically discretized to the model grid. In the future, this function will be strengthened.

\section{MODEL GENERATION}

All modeling parameters could be entered through interactive graphics or easy-to-used dialog boxes. When saving this model, these values will be written into input files, according to the format of TOUGHREACT. There is no need to worry about formatting text files to run the models, nor need to have the aid of visualization ability of other softwares after the model run.

\section{A. Generating Input File}

\section{1) "Flow.inp"}

This file mainly includes rock properties, time-stepping information, geometric grid information, initial and boundary conditions, and additional data related to a multi-phase fluid and heat flow simulation [15].

2) "Solute.inp"

This "solute.inp" file in the original TOUGHREACT program contains various flags and input parameters for calculations of reactive transport [22], such as diffusion coefficients, transport parameters, tolerance limits, and output control. Parameters in this file are organized in various displayed menus, as previously mentioned.

3) "Chemical.inp"

This file is used to define the geochemical system, including number of aqueous component species, minerals, gases, and sorbed species considered in the simulation [22]. The file also contains the initial chemical composition of water, minerals, and gases for different zones that are assigned to grid blocks. This interface allows a user readily define or associate the geochemical parameters and properties to grid blocks.

\section{B. Running Model}

Once TOUGHREACT input files are saved, model can be launched by selecting Run command from the TOUGHVISUAL menu. If the simulation has not been saved, the interface will prompt you to save the simulation before model run. Then a dialog box will appear (Fig. 15). There are three graph types, including Time step versus Number of iterations, Error versus Number of iterations, and Simulation-Time progress versus Number of iterations, to indicate calculation progress. For different graph types, the user will receive different information.

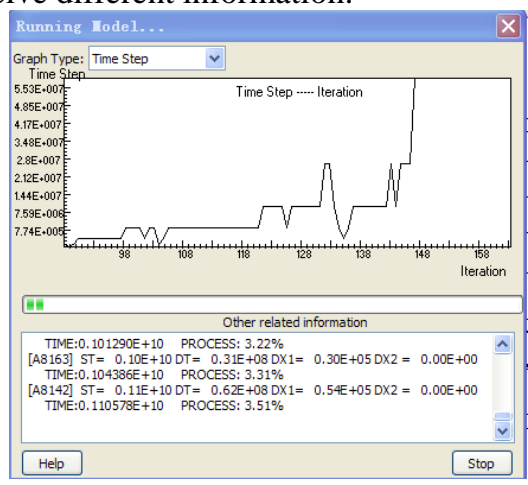

Figure 15. Simulation progress and time step size. 


\section{VISUALIZATION}

The fast visualization of modeling results is very important, so that dynamic analysis can be conducted interactively. During the model building process, the graphical representation of the model allows you to review and present simulation results quickly, and someone else can easily see and understand the parameters of your analysis. For visualizing the modeling results, post-processing has been developed, including 3D iso-surfaces, contour maps, cross sections and temporal evolution plots. In addition, modeling results can be displayed by cartoon (AVI format file for external play can also be saved)

a

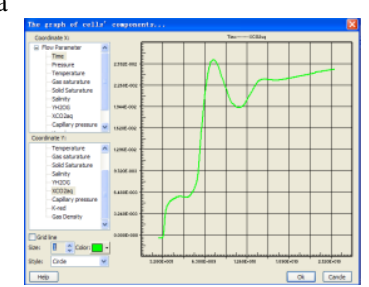

b

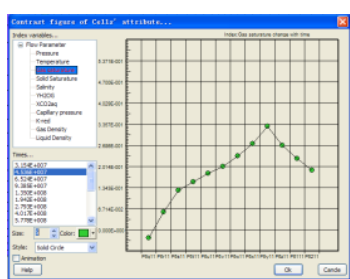

c

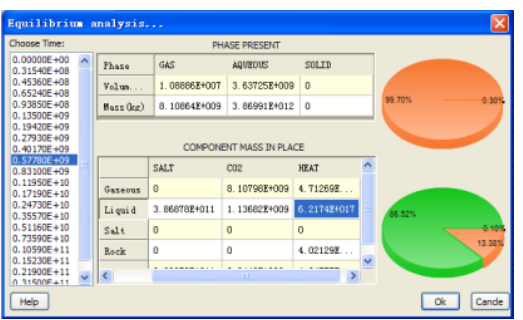

Figure 16. (a) Temporal evolution for one grid block. (b) Attributed plot for multiple elements. (c) Component distribution plot at different times.

For one or more grid blocks, the user can plot resulting variables in terms of temporal evolution (Fig. 16a and b). In many instances, it is very useful to display the distribution of each component in one model (Fig. 16c), and different times would have different distribution.

Choosing the cell-center point as the calculation nodes, needs to convert the attribute value to the cell-vertex (Fig. 17), in order to draw various maps. This interface calculates the cell-vertex attribute value, according to the neighboring cell-center weighted interpolation algorithm. The IDW method $[3,4,10,11,18]$ is simpler to program, and it does not require pre-modeling, and consumes less calculation time, it provides a measure of uncertainty of the estimates that is directly related to the values being estimated. The IDW algorithm, applied to each location being estimated, is based on Equation 5. Other interpolation methods will be introduced in the future development.

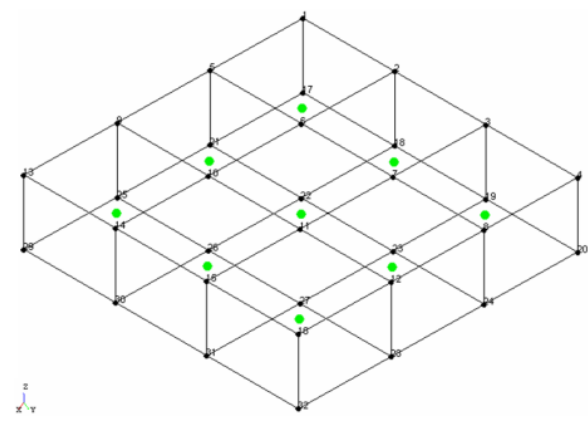

Figure 17. Center node and grid vertex (green points are the center nodes, while the black points are the grid vertex).

$$
v_{j}=\sum_{i=1}^{n} z_{i} /\left(h_{i j}+\delta\right)^{\beta} / \sum_{i=1}^{n} 1 /\left(h_{i j}+\delta\right)^{\beta}
$$

where $v_{j}$ is the interpolated value of a grid vertex, $z_{i}$ is the value of neighboring cell-center nodes, $h_{i j}$ are the distances between the cell-center nodes and cell-vertex points, $\beta$ is the weighting power, and $\delta$ is the smoothing parameter. $n$ is the number of neighboring data points; $h_{i j}$ (distance) calculated by a simple Euclidean distance equation: $\quad h_{i j}=\sqrt{\left(x_{i}-x_{j}\right)^{2}+\left(y_{i}-y_{j}\right)^{2}+\left(z_{i}-z_{j}\right)^{2}}$

\section{APPLICATION EXAMPLES}

Here we present two examples to illustrate the advantages and applicability of the interface software TOUGHVISUAL. Through mouse clicking, one can complete the pre-processing for generating input files for TOUGH2 and TOUGHREACT, run model simulation, and then perform the post-processing for viewing the simulation result interactively.

\section{A. Case Study 1: CO2 Geological Storage}

The geometry of this model for a $\mathrm{CO} 2$ injection problem is shown in Fig. 18. Each geological layer is color-coded, and the properties of each layer can be varied, especially the mineralogical and hydraulic properties. The most important hydrogeological parameters used are listed in Table 1. The storage system is idealized as a 2D symmetric domain, so the model needs only to cover one half of the domain. This model contains 108,000 elements (grid blocks), with 316,740 connections. The $\mathrm{CO} 2$ injection rate at the well is specified at $32 \mathrm{~kg} / \mathrm{s}$ (one million ton per year) in the 18th layer for a time period of 40 years. 
TABLE I. HYDROGEOLOGICAL PARAMETERS FOR THE 3D CO2 INJECTION PROBLEM

\begin{tabular}{|c|c|c|c|c|c|c|c|}
\hline \multicolumn{2}{|c|}{ Property } & SHAL1 & AQUI1 & SHAL2 & AQUI2 & SHAL3 & $\begin{array}{l}\text { FAU } \\
\text { LT }\end{array}$ \\
\hline \multirow{2}{*}{$\begin{array}{l}\text { Permea } \\
\text { bility } \\
\left(\mathrm{m}^{2}\right)\end{array}$} & $\begin{array}{c}\text { Horizonta } \\
1\end{array}$ & $\frac{1.0 \times 10^{-}}{16}$ & $\frac{1.0 \times 10^{-}}{13}$ & $\frac{1.0 \times 10^{-}}{16}$ & $\underset{13}{1.0 \times 10^{-}}$ & $\frac{1.0 \times 10^{-}}{16}$ & $\begin{array}{l}1.0 \times \\
10^{-13}\end{array}$ \\
\hline & Vertical & $\underset{17}{1.0 \times 10^{-}}$ & $\underset{14}{1.0 \times 10^{-}}$ & $\underset{17}{1.0 \times 10^{-}}$ & $\underset{14}{1.0 \times 10^{-}}$ & $\underset{16}{1.0 \times 10^{-}}$ & $\begin{array}{l}1.0 \times \\
10^{-13}\end{array}$ \\
\hline \multicolumn{2}{|l|}{ Porosity } & 0.058 & 0.15 & 0.058 & 0.1 & 0.058 & 0.1 \\
\hline \multicolumn{2}{|c|}{ Compressbility } & \multicolumn{6}{|c|}{$\left.4.5 \times 10-10\left(\mathrm{~Pa}^{-1}\right)\right)$} \\
\hline \multicolumn{2}{|l|}{ Density } & \multicolumn{6}{|c|}{$2600\left(\mathrm{~kg} / \mathrm{m}^{3}\right)$} \\
\hline \multicolumn{2}{|c|}{ Temperature } & \multicolumn{6}{|c|}{$45\left({ }^{\circ} \mathrm{C}\right)$} \\
\hline \multicolumn{2}{|l|}{ Pressure } & \multicolumn{6}{|c|}{$1.013 \times 10^{8}(\mathrm{~Pa})$} \\
\hline \multicolumn{2}{|l|}{ Salinity } & \multicolumn{6}{|c|}{0.1} \\
\hline \multicolumn{2}{|c|}{$\mathrm{CO} 2$ injection rate } & \multicolumn{6}{|c|}{$32(\mathrm{~kg} / \mathrm{s})$} \\
\hline \multicolumn{8}{|c|}{ Relative permeability parameter } \\
\hline \multicolumn{2}{|c|}{$\begin{array}{l}\text { Liquid (Van } \\
\text { enuchten,1980) }\end{array}$} & \multicolumn{6}{|c|}{$k_{l r}=\sqrt{S^{*}}\left\{1-\left(1-\left[S^{*}\right]^{1 / m}\right)^{m}\right\} S^{*}=\left(S_{l r}-S\right) /\left(1-S_{l r}\right) \quad S_{l r}=0.20$} \\
\hline \multicolumn{2}{|c|}{$\begin{array}{l}\text { Irreducible water } \\
\text { saturation (Corey, } \\
\text { 1980) }\end{array}$} & \multicolumn{6}{|c|}{$k_{r g}=(1-\hat{S})^{2}\left(1-\widehat{S}^{2}\right) \hat{S}=\left(S_{l}-S_{l r}\right) /\left(S_{l}-S_{l r}-S_{g r}\right) \mathrm{s}_{\mathrm{gr}}=0.05$} \\
\hline \multicolumn{8}{|c|}{ Capillary pressure parameters } \\
\hline \multicolumn{2}{|c|}{$\begin{array}{l}\text { Van Genuchten } \\
(1980)\end{array}$} & \multicolumn{6}{|c|}{$P_{c a p}=-P_{0}\left(\left[S^{*}\right]^{1 / m}-1\right)^{-m} S^{*}=\left(S_{l}-S_{l r}\right) P_{0}=\rho_{w g} / \alpha \mathrm{m}=0.40$} \\
\hline
\end{tabular}

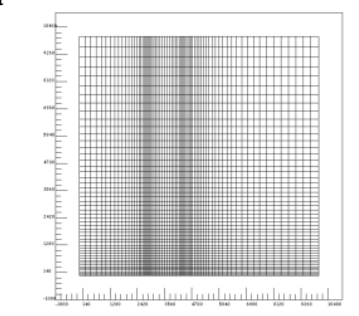

b

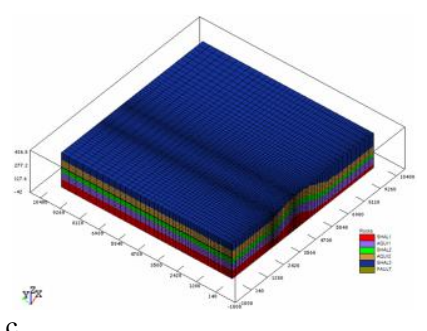

$\mathrm{c}$

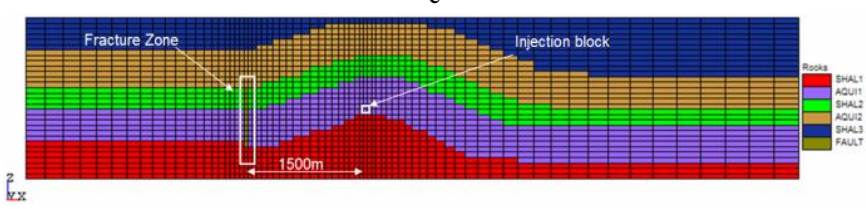

Figure 18. Conceptual model with rectangular grids for a $\mathrm{CO} 2$ storage system. (a) Layout of a geological layer. (b) Grid lithological model, coming from the stratigraphical model transformation. (c) Cross-section of the lithological diagram.

There are six rock material zones for this model, as shown in Fig. 18b. The lateral boundaries are far from the injection point and assumed no-flow. Top and bottom are shale layers, are assumed impermeable. The initial temperature is calculated according to geothermal gradient of $30^{\circ} \mathrm{C} / \mathrm{km}$ from the top temperature of $45^{\circ} \mathrm{C}$, and the initial pressure is calculated according to hydrostatic distribution with the top of the system at a depth of $1.0 \mathrm{~km}$. The simulation runs cover a time period of 1000 years including a $\mathrm{CO} 2$ injection period of 40 years.

By setting the iso-surface options, iso-surface map of $\mathrm{P}$, $\mathrm{T}$, and other state variables will be produced. Fig. 19 shows the simulated results after different times. Image details can be controlled, for instance, the number of iso-surfaces/isoline and the data range. If only one time step is selected, the contour map will overlay the finite-difference grid. If more than one time step are selected, then the selected contour maps would be dynamically shown. For super-critical CO2 gas saturation, the stratum structure and shale layer acts as a barrier to the upward $\mathrm{CO} 2$ migration, due to buoyancy and increased pressure by injection. In this case, leakage begins at about 75 years alone the vertical fracture zone. After 78.4 years, the plume enters slightly into the shallower region, and the plume extends over a range of 3-4 $\mathrm{km}$ in the $\mathrm{X}$ and $\mathrm{Y}$ direction.

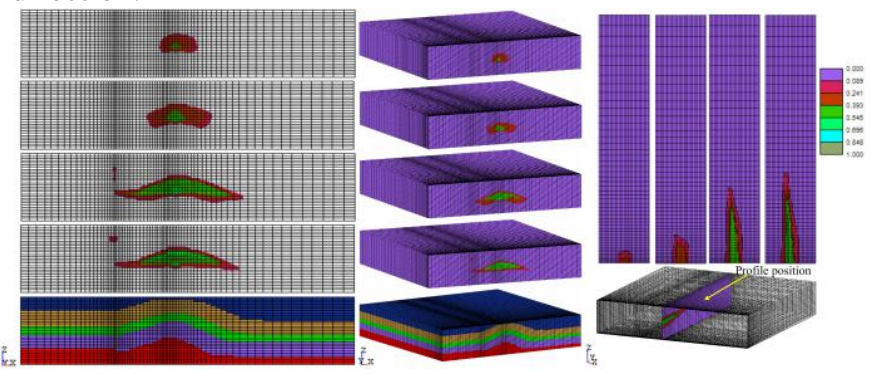

Figure 19. Distribution of $\mathrm{CO} 2$ gas saturation at the different times (2.07, $8.86,78.4,162.2$ years).

To investigate the long-term fate and transport of injected $\mathrm{CO} 2$ in the storage reservoir, a 3D model was set up based on case 1. However, there are so many elements (grid blocks) and connections in that model, which needs much calculation time, therefore, it need to reduce the number of elements and connections reasonably. Hydrogeologic parameters and water chemical composition come from some papers $[22,26]$.

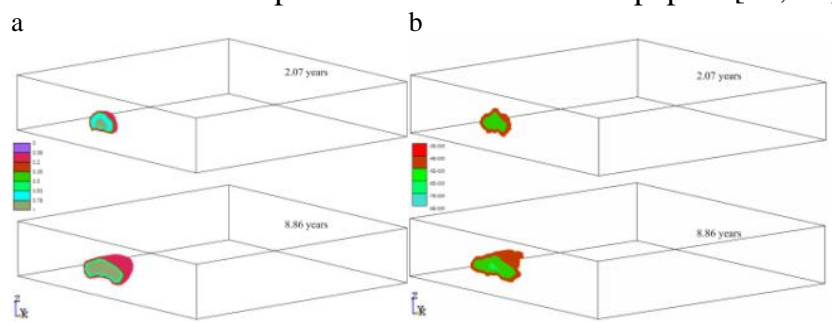

Figure 20. (a) Distribution of total dissolved CO2 (mol/ $\mathrm{kg} \mathrm{H} 2 \mathrm{O})$ at different times; (b) Distribution of calcite abundance at different times.

Fig. 20 are the iso-surface map of dissolved $\mathrm{CO} 2$ and calcite in 3D. Fig 20a presents the simulated total dissolved $\mathrm{CO} 2$ concentration after different times. The concentration of dissolved $\mathrm{CO} 2$ gradually increases with the injected $\mathrm{CO} 2$. it will form $\mathrm{H} 2 \mathrm{CO} 3, \mathrm{HCO} 3-$, and $\mathrm{CO} 32$ - and decrease $\mathrm{pH}$ in the surrounding water. Then, the decreased acidity leads to dissolve many of the primary minerals, such as calcite in the two-phase region and near the front of the single aqueousphase zone (Fig 20b).

\section{B. Case Study 2: Enhanced geothermal system}

The development of enhanced geothermal system using $\mathrm{CO} 2$ as working fluid (CO2-EGS) is a promising idea for expanding geothermal energy production. Here, we utilize this interface to build an EGS model. This model is a five- 
spot geothermal reservoir (Fig. 21a) with injection and production as described by Pruess [15]. The 3D conceptual model is shown in Fig. 21b. The formation has a geothermal gradient of $35^{\circ} \mathrm{C} / \mathrm{km}$ from a surface temperature of $20^{\circ} \mathrm{C}$, and the top layer pressure is $1.96 \times 107 \mathrm{~Pa}$. This reservoir is subdivided into 2460 grid blocks. Super critical CO2 is injected at a constant pressure of $4 \mathrm{MPa}$ above hydrostatic (lower left) into a water-saturated geothermal reservoir, and the production keeps a constant pressure of $4 \mathrm{MPa}$ below hydrostatic (upper right). The fluid dynamics and thermal parameters used are given in Table 2.

a

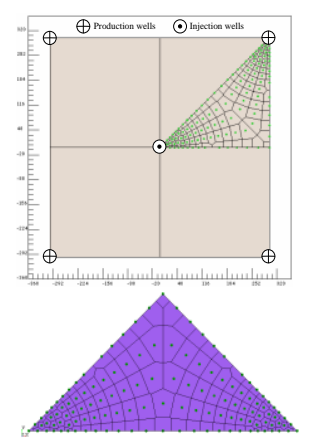

b c

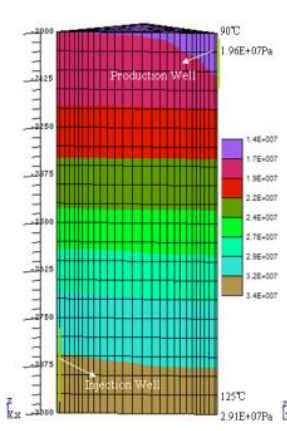

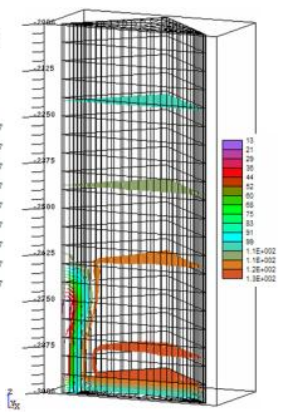

Figure 21. (a) A plan view of the Voronoi discretization used in the CO2EGS model, the green point is the grid block's center. (b) The 3D plot of pressure distribution after 1 year showing the injection (lower left) and production (upper right). (c) Simulated temperature distribution after 1 years

TABLE II. PARAMETERS USED FOR CO2-EGS SIMULATIONS.

\begin{tabular}{|c|c|c|c|}
\hline Density $(\mathrm{kg} / \mathrm{m} 3)$ & 2650 & Porosity & 0.1 \\
\hline $\begin{array}{l}\text { Heat conductivity } \\
\left(\mathrm{W} / \mathrm{m}^{\circ} \mathrm{C}\right)\end{array}$ & 2.5 & $\begin{array}{l}\text { Rock grain specific heat } \\
\left(\mathrm{J} / \mathrm{kg}^{\circ} \mathrm{C}\right)\end{array}$ & 1000 \\
\hline \multicolumn{4}{|c|}{ Relative permeability parameter } \\
\hline $\begin{array}{l}\text { Liquid (Van } \\
\text { genuchten,1980) }\end{array}$ & \multicolumn{3}{|c|}{$k_{l r}=\sqrt{S^{*}}\left\{1-\left(1-\left[S^{*}\right]^{\prime \prime m}\right)^{m}\right\} S^{*}=\left(S_{l r}-S\right) /\left(1-S_{l r}\right) S_{l r}=0.15$} \\
\hline $\begin{array}{l}\begin{array}{l}\text { Irreducible } \\
\text { saturation } \\
1980)\end{array} \\
\text { (Corey, }\end{array}$ & \multicolumn{3}{|c|}{$\hat{S}=\left(S_{l}-S_{l r}\right) /\left(S_{l}-S_{l r}-S_{g r}\right) k_{r g}=(1-\hat{S})^{2}\left(1-\hat{S}^{2}\right) \mathrm{S}_{\mathrm{gr}}=0.05$} \\
\hline \multicolumn{4}{|c|}{ Capillary pressure parameters } \\
\hline $\begin{array}{l}\text { Van } \\
(1980)\end{array}$ & \multicolumn{3}{|c|}{$P_{c a p}=-P_{0}\left[\left(S^{*}\right]^{1 / n}-1\right)^{-n} S^{*}=\left(S_{l}-S_{l r}\right) P_{0}=\rho_{w g} / \alpha \mathrm{m}=0.457$} \\
\hline
\end{tabular}

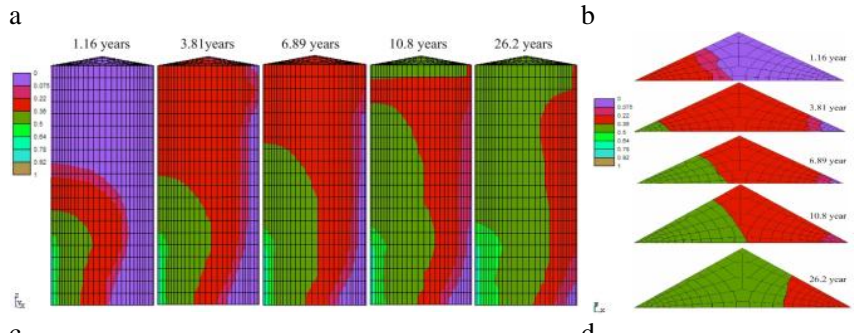

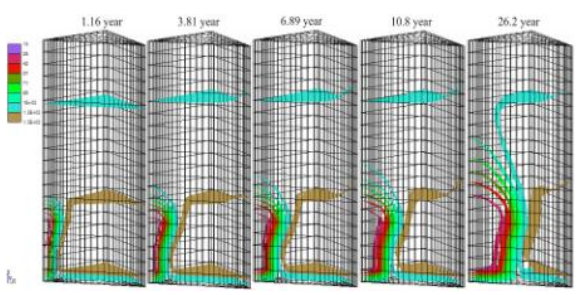

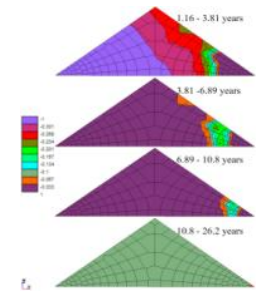

Figure 22. CO2-EGS model results. (a) $\mathrm{CO} 2$ gas saturation distribution at different times. (b) Temperature iso-surface distribution at different times (c) Gas saturation distribution at different times at the tenth layer. (d) Gas saturation variation diagram between two time points

The model result can be shown with two sets of figures; one set (Fig 22a and c) describes the 3D distribution of variables at $\mathrm{t}=1.16,3.81,6.89,10.8$ and 26.2 years. While the second set (Fig 22b and d) describes the state variables over time evolution or between two time points, for a specified one layer. It takes about four years for the $\mathrm{CO} 2$ plume to reach the production well.

\section{CONCLUSIONS}

The user-friendly interface software (TOUGHVISUAL), can easily generate regular or irregular meshes. Then they can be locally refined and adjusted to apply computing resource more effectively. The model parameters can be edited or transformed from other modules. The modeling output from TOUGHREACT run can be visualized interactively in different ways, including temporal evolution curves, space iso-surfaces, contour of a cross-sectional map. Model data can be conveniently managed for checking and modifying. It is made up of several modules, which can help to set up models, such as the conceptual model approach, complex geologic model to numerical model. The program can read or write some common file data, and can provide sharing data interface with other softwares. In addition, the input menus represent the basic "model building blocks" for assembling a data set for TOUGHREACT, these menus are design in the logical order to guide the user through the steps necessary to design a model.

Two different application cases are presented here to illustrate the applicability of this interface. We only present 3D maps here, but it can also display temporal evolution curves of various state variables in $2 \mathrm{D}$ plots. It has been demonstrated that this flexible interface can contribute to set up TOUGHREACT or TOUGH2 models particularly with a complex geology, and can effectively visualize the simulation results in a timely manner.

\section{ACKNOWLEDGMENT}

This work was supported by Jilin University's Groundwater Resources and Environments Key Laboratory of Ministry of Education (China), by National Natural Science Foundation of China (No. 41272254), the China Geological Survey project (No. 12120113006300), public welfare industry special funds for scientific research from the Ministry of Land and Resources of China (No.201211063), the doctoral interdisciplinary scientific research project of 
Jilin University (No.2012DC014) and the Graduate Innovation Fund of Jilin University (No.20121069).

\section{REFERENCES}

[1] Alcott, A., Swenson, D., Hardeman, B., 2006. Using Petrasim to create, execute, and post-process TOUGH2 models. In: Proceedings of the TOUGH Symposium, Lawrence Berkeley National Laboratory, Berkeley, California, May 15-17.

[2] Burnell, J.G., White, S.P., Osato, K., Sato, T., 2003. GeoCad, a pre and postprocessor for TOUGH2. In: Proceedings of the TOUGH Symposium, Lawrence Berkeley National Laboratory. Berkeley, California, May 12-14.

[3] Calcagno, P., Chil_es, J.-P., Courrioux, G., Guillen, A., 2008. Geological modelling from field data and geological knowledge. Part I. Modelling method coupling 3D potential-field interpolation and geological rules: recent advances in computational geo dynamics: theory, numeric sand applications. Physics of the Earth and Planetary Interiors 171(1-4), 147-157.

[4] Caruso, C. and F. Quarta, 1998. Interpolation methods comparison. Computers \& Mathematics with Applications 35, 109-126.

[5] Díaz Patiño, J.C., R. Pacheco, M. César Suárez Arriaga,2006. Some Topological Aspects of (Un)Structured Generation of Meshes: A Possible Enhancement of Meshmaker in TOUGH, Proceedings of TOUGH Symposium 2006, Lawrence Berkeley National Laboratory, Berkeley, California, May 15-17.

[6] Dyer, M. E. and A. M. Frieze, 1988. On the complexity of computing the volume of a polyhedron. SIAM J. Comput. 17, 967-974.

[7] Frey, W. H., 1987. Selective refinement: a new strategy for automatic node placement in grade triangular meshes. International Journal for Numerical Methods in Engineering, 24, 2183-2200.

[8] Gelder, A. V., 1995. Efficient Computation of Polygon Area and Polyhedron. Graphics Gem, 4th edition. Academic Press.

[9] Gellert, W.; Gottwald, S.; Hellwich, M.; Kästner, H.; and Künstner, H. (Eds.). 1989,VNR Concise Encyclopedia of Mathematics, 2nd ed. New York: Van Nostrand Reinhold.

[10] Lu, G. Y. and D. W. Wong, 2008. An adaptive inverse-distance weighting spatial interpolation technique. Computers \& Geosciences 34, 1044-1055

[11] Mallet, J. L., 1992. Discrete smooth interpolation in geometric modelling. Computer-Aided Design 24, 178-191.

[12] Narasimhan, T.N.,Witherspoon, P.A., 1976. An integrated finite difference method for analyzing fluid flow in porous media. Water Resources Research 12, 57-64.

[13] Nilforoushan, Z., Mohades, A., 2010. 3D hyperbolic Voronoi diagrams. Computer-Aided Design 42, 759-767.

[14] Pruess, K., 2004. The TOUGH codes: a family of simulation tools for multiphase flow and transport processes in permeable media. Vadose Zone Journal 3 , 738-746.
[15] Pruess, K., Oldenburg, C., Moridis, G., 1999. TOUGH2 user's guide, version 2.0, Lawrence Berkeley National Laboratory. Berkeley, California, USA, Report LBNL-43134, 198pp.

[16] Pan, L.,2003.WinGridder: an interactivegridgeneratorforTOUGH2. In: ProceedoftheTOUGHSymposium.LawrenceBerkeleyNationalLaboratory, Berkeley, California, May 12-14.

[17] Sadoyan, H., Zakarian, A., 2006. Robust uniform triangulation algorithm for computer aided design. Computer-Aided Design 38, 1134-1144.

[18] Sun, Y., Kang, S., 2009. Comparison of interpolation methods for depth to groundwater and its temporal and spatial variations in the Minqin oasis of northwest China. Environmental Modelling \& Software 24, 1163-1170.

[19] Xu, T., Pruess, K., 2001. Modeling multiphase non-isothermal fluid flow and reactive geochemical transport in variably saturated fractured rocks: 1. Methodology. Americal Journal of Science 301, 16-33.

[20] Xu, T., Spycher, N., 2011. TOUGHREACT Version 2.0: A simulator for subsurface reactive transport under non-isothermal multiphase flow conditions. Computers \& Geosciences 37, 763-774.

[21] Xu, T., Sonnenthal, E., Spycher, N., Press, K., 2005. TOUGHREACT User's guide: A simulation program for non isothermal multiphase reactivegeochemical transport in variably saturated geologicmedia, Lawrence Berkeley national Laboratory. Berkeley, California, USA, Report LBNL-55460,192p.

[22] Xu, T., Sonnenthal, E.L., Spycher, N., and Pruess, K., 2006 TOUGHREACT: A Simulation Program for Non-isothermal Multiphase Reactive Geochemical Transport in Variably Saturated Geologic Media. Computers \& Geosciences 32, 145-165.

[23] Yamamoto, H., 2008. PertraSim: a Grapical User Interface for the TOUGH2 family of multiphase flow and transport code. Ground Water 46, 525-528.

[24] Yang, Y., Xu, T., Wang, F.: Toughvisual: a user-friendly preprocessing and post-processing graphical interface for TOUGHREACT. In: Proceedings TOUGH Symposium 2012, Lawrence Berkeley National Laboratory, Berkeley, California, September 17-19 (2012)

[25] Y. Li, M. Niewiadomski, E. Trujillo, and S.P. Sunkavalli, 2011. Tougher: A user-friendly graphical interface for TOUGHREACT. Computers \& Geosciences, 37, 775-782.

[26] Zhang, K., Wu, Y.S., 2006, Enhancing scalability and efficiency of the TOUGH2-MP for linux clusters. In: Proceedings of the TOUGH Symposium 2006, Berkeley, CA.

[27] Zheng, L., Apps, J.A., Zhang, Y., Xu, T., Birkholzer, J., 2009. On mobilization of lead and arsenic in groundwater in response to $\mathrm{CO} 2$ leakage from deep geological storage. Chemical Geology 268, 281297. 